\title{
Determination of Occupational Stress and Its Related Factors in Female Staff of Kashan University of Medical Sciences
}

\author{
Research Article
}

\begin{abstract}
Hamid Reza Saberi ${ }^{1}$, Saba Karimi ${ }^{2 *}$, Masoud Motalebi Kashani ${ }^{3}$
1. Occupational medicine specialist,,Associate Professor, Kashan University of Medical Sciences, Social Determinants Health Research Center, Kashan, Iran.

2. Instructor, Faculty of Nursing and Midwifery, Kermanshah University of Medical Sciences, Kermanshah. Iran. 3. Occupational Health Specialist. Associate Professor, Kashan University of Medical Sciences, Social Determinants Health Research Center, Kashan, Iran.

Abstract

Background and Aim: The phenomenon of stress is one of the fundamental problems in the last few decades following the changes and developments of societies and the advent of modern life that has put people at risk. The aim of this study was to determine the level of occupational stress and its related factors in female staff of Kashan University of Medical Sciences. Methods: This is a cross-sectional descriptive study and the sample size was all female employees (132 persons) working in faculties and departments of Kashan University of Medical Sciences in 2016. The UK HSE occupational stress questionnaire was used to measure occupational stress. Data were imported into SPSS16 software and analyzed using Chi-square and Fisher exact test. Findings: Only two variables showed a significant statistical relationship with job stress; hours of work and the workplace (P-value $<0.05)$, but there was no significant statistical relationship between job shift, education level and employment status (P-value $>0.05)$. Conclusion: The high level of occupational stress among employees of the deputies indicate the importance of reducing the working hours of the staff to the standard working hours of other countries, as well as the periodic shift of staff from the deputies to the faculties.
\end{abstract}

Keywords: Job stress, Employees, Women, Kashan .

\section{Introduction}

One of the major problems that has been putting people at risk in recent decades, following the development of societies and turning to modern life, is the phenomenon of stress (1). Stress is a force that, when applied to a system, causes some significant changes. This term refers to physical, psychological, social and pressure forces $(6,-2)$. Job stress can be associated with multiple psychological, physical and organizational problems (7.8). Employees are among the people who are suffering from this phenomenon in various organizations (9). In addition to being exposed to environmental, socio-economic, cultural and familial stressors, government employees are also faced with job stress as a member of the government (10). Research shows that the workplace environment and occupational stress can cause illness in employees or accelerate the process of developing the disease (11).

Schenker and Famwiawa have reported that low levels of mental health are associated with high levels of job stress (12). Extreme psychological stress imposes high costs on the organization and the individual by reducing productivity and motivation, lack of work, strikes and absenteeism (13). Stress and its complications result in the loss of hundreds of working

*Corresponding Author:

\section{Saba Karimi}

Instructor, Faculty of Nursing and Midwifery,

Kermanshah University of Medical Sciences,

Kermanshah. Iran.

Email id: kariminursing@yahoo.com days each year. It has been estimated that around 30\% of the workforce in the developed countries suffers from occupational stress $(14,15)$. The European Institute for Occupational Safety and Health reports that over half of the 550 million working days lost annually in the United States are due to job absenteeism caused by occupational stress $(16,17)$. Many studies at inside the country and abroad have shown that women are at varying degrees affected by job stress (18). Molaei et al. investigated the level of job stress in employed women in Ardebil in 2009, which showed that $62.8 \%$ of working women had moderate stress and $36.5 \%$ suffered from severe stress (19).

Mugavero's study showed that employed women report health problems about $40 \%$ more than their male counterparts and are significantly more stressed out (20). Further studies have shown that a high proportion of female laborers in the United States face job pressure, and the majority of female workers experience stress from workplace discrimination $(19,21)$. Also, in other studies, job stress has been associated with chronic sleep disorders (22-24), since women have become more likely to be in workplaces in the last few decades, and since women working in the field of medical science plays a number of roles in the society and the family, their mental health has a direct impact on the mental health of the family and their working environment, therefore, given the importance of this issue, and because there are few studies in this area, our aim is to determine the level of occupational stress and its related factors among female staff of Kashan University of Medical Sciences. 


\section{Method}

This study was descriptive cross-sectional. The research population was all the female staff (132 persons) working in faculties (medicine, health, paramedical, nursing and midwifery) and deputy (health, treatment, education, research, food and drug, student and cultural) of Kashan University of Medical Sciences in 2016. Sampling method was census. The sample size was 132 female staff of Kashan University of Medical Sciences. The research environment was considered to be all the faculties and departments of Kashan University of Medical Sciences. To assess job stress, the HSE (Health and Safety Executive) questionnaire was used for 7 areas: demand, control and support of authorities, support of colleagues, communication, role and changes. Which consists of two parts, the first part examining the demographic characteristics, and the second part has 35 components.

The questionnaire consists of five options (never, rarely, sometimes, often, and always) of the Likert spectrum. It should be noted that questions 22, 34 and, $20,21,18,16,14,12,3,5,6,9$ in this questionnaire, are reversed. So that the option 'never' gets a score of 5 and 'always' get a score of 1 . After obtaining the score of each statement, the subscales are obtained as follows. The high score in this questionnaire reflects the low and appropriate stress and pressure of the job, as well as the low scores for the higher stress markers. The questionnaire was designed in 1990 with the guidance and direction of the UK Department of Labor and Safety to identify job stressors. The validity of this questionnaire was determined in a study by Esfandiar
Marzabadi and its reliability was calculated by Cronbach's alpha as 0.78 (17). After obtaining a research license from Kashan University of Medical Sciences, the researcher referred to the medical centers of Kashan University of Medical Sciences. After being present in these centers, and obtaining the consent of each organization, the researcher explained the method and the purpose of this study to sample participant in the research, and after obtaining the written and oral consent of Kashan female medical staff, the HSE demographic and occupational information questionnaire was completed by these employees. The feature to exit the study included the reluctance of employees to participate in the program. After collecting information, the researchers extracted the necessary information from the registration forms, imported into software SPSS16 and analyzed data using descriptive statistics. This article is the result of a research project with Code 1563 at Kashan Medical School.

\section{Findings}

Among the subjects, $82.6 \%$ (109 people) had only morning shift; most of them $(71.2 \%, 94$ people) had undergraduate and associate degrees. Also, most of the participants were married $(90.9 \%, 120$ people) 62 people $(47 \%)$ of these employees had an income between 500 and 700 thousand Tomans per month; most of them $(47.7 \%)$ were official employees and $(37.1 \%)$ had 20 years or more work experience; Finally, 91 of them $(68.9 \%)$ had children (Table 1$)$.

Table 1. Percent and frequency of individuals in the studied variables

\begin{tabular}{|c|c|c|c|}
\hline & ariable & $\begin{array}{l}\text { Absolute } \\
\text { frequency }\end{array}$ & $\begin{array}{c}\text { Percentage of relative } \\
\text { frequency }\end{array}$ \\
\hline \multirow[b]{2}{*}{ Hours of work } & Under 8 hours & 43 & 32.6 \\
\hline & 8 hours and up & 89 & 67.4 \\
\hline \multirow{2}{*}{ Shift work } & Just morning & 109 & 82.6 \\
\hline & Circulation & 23 & 17.4 \\
\hline \multirow{3}{*}{ Education } & Diploma and lower & 32 & 24.2 \\
\hline & Undergraduate and Bachelor & 70 & 53 \\
\hline & Senior and higher & 30 & 22.7 \\
\hline \multirow{2}{*}{ Workplace } & Deputies & 94 & 71.2 \\
\hline & University faculties & 38 & 28.8 \\
\hline \multirow[t]{2}{*}{ Marital status } & Single & 12 & 9.1 \\
\hline & Married & 120 & 90.9 \\
\hline \multirow{3}{*}{ Income } & 350 to 500 thousand Tomans & 43 & 32.6 \\
\hline & 500 to 700 thousand Tomans & 62 & 47 \\
\hline & More than 700 thousand Tomans & 26 & 20.5 \\
\hline \multirow{3}{*}{ Employment status } & Official & 63 & 47.7 \\
\hline & Contractual & 51 & 38.6 \\
\hline & A treaty & 18 & 13.6 \\
\hline \multirow{3}{*}{ Work experience } & under 10 years old & 48 & 36.4 \\
\hline & 10 to 20 years & 35 & 26.5 \\
\hline & 20 years and more & 49 & 37.1 \\
\hline \multirow{2}{*}{ Child } & Has it & 91 & 68.9 \\
\hline & does not have & 41 & 31.1 \\
\hline
\end{tabular}


In Table 2, as can be seen, all areas of occupational stress, with the exception of the "role" (demand, control, support of authorities, support of colleagues, communication, changes, and HSE occupational stress), demonstrate a statistically significant relationship with the location of the work of the surveyed staff. According to the findings, employees in deputies will have a significantly higher job stress than employees in faculties $(\mathrm{P}$-value $<0.05)$.

On the other hand, during the study on the areas identified for occupational stress, it was observed that the domains of "occupational stress" in these employees had a statistically significant relationship with the two variables; work place and working hours (P-value $<0.05)$; however, there was no significant relationship with educational, marital, income and employment status (P-value $>0.05)$.

Table 2. Frequency distribution of occupational stress in different areas by job

\begin{tabular}{|c|c|c|c|c|}
\hline \multicolumn{2}{|c|}{ Variable } & College & Assistance & p-value \\
\hline \multirow{2}{*}{ Demand } & Average & 22.3 & 25.02 & \multirow{2}{*}{0.018} \\
\hline & Standard deviation & 4.83 & 5.5 & \\
\hline \multirow{2}{*}{ Control } & Average & 12.8 & 14.56 & \multirow{2}{*}{0.029} \\
\hline & Standard deviation & 3.41 & 3.85 & \\
\hline \multirow{2}{*}{ Sponsor support } & Average & 13.46 & 15.44 & \multirow{2}{*}{0.021} \\
\hline & Standard deviation & 4.15 & 3.87 & \\
\hline \multirow{2}{*}{ Partner support } & Average & 9.23 & 11.26 & \multirow{2}{*}{0.006} \\
\hline & Standard deviation & 4.15 & 3.43 & \\
\hline \multirow{2}{*}{ Relationship } & Average & 7.7 & 9.32 & \multirow{2}{*}{0.025} \\
\hline & Standard deviation & 2.64 & 3.56 & \\
\hline \multirow{2}{*}{ Role } & Average & 8.4 & 9.22 & \multirow{2}{*}{0.242} \\
\hline & Standard deviation & 3.47 & 3.25 & \\
\hline \multirow{2}{*}{ Changes } & Average & 7.3 & 8.97 & \multirow{2}{*}{0.004} \\
\hline & Standard deviation & 2.35 & 2.8 & \\
\hline \multirow{2}{*}{ HSE job stress } & Average & 85.4 & 98.3 & \multirow{2}{*}{0.001} \\
\hline & Standard deviation & 15.41 & 17.63 & \\
\hline
\end{tabular}

Table 3: Relationship between job stress and demographic variables

\begin{tabular}{|c|c|c|c|}
\hline \multicolumn{2}{|r|}{ Job stress } & \multirow{2}{*}{ Mean \pm standard deviation } & \multirow{2}{*}{ p-value } \\
\hline & Variable & & \\
\hline \multirow{3}{*}{ Education } & Tips and diplomas & $3 \pm 97.2$ & \multirow{3}{*}{$\mathrm{P}=0.51$} \\
\hline & Undergraduate Diploma & $97.3 \pm 3.5$ & \\
\hline & Master's degree and higher & $97.25 \pm 5.7$ & \\
\hline \multirow{2}{*}{ Workplace } & University faculties & $85.4 \pm 15.41$ & \multirow{2}{*}{$\mathrm{P}=0.001$} \\
\hline & Deputies & $98.3 \pm 17.63$ & \\
\hline \multirow{2}{*}{ Marital status } & Single & $96.3 \pm 3.2$ & \multirow{2}{*}{$\mathrm{P}=0.8$} \\
\hline & Married & $96.2 \pm 4.1$ & \\
\hline \multirow{2}{*}{ Income } & Less than 500 thousand Tomans & $96.12 \pm 17.83$ & \multirow{2}{*}{$\mathrm{P}=0.21$} \\
\hline & More than 500 thousand Tomans & $91.27 \pm 18.07$ & \\
\hline \multirow{3}{*}{ Employment status } & Official & $97.28 \pm 3.1$ & \multirow{3}{*}{$\mathrm{P}=0.79$} \\
\hline & Contractual & $97.26 \pm 3.6$ & \\
\hline & A treaty & $97.23 \pm 5$ & \\
\hline \multirow{2}{*}{ Work experience } & Less than 10 years & $93.78 \pm 18.97$ & \multirow{2}{*}{$\mathrm{P}=0.56$} \\
\hline & More than 10 years & $95.77 \pm 17.15$ & \\
\hline \multirow{2}{*}{ Hours of work } & Less than 8 hours & $87.1 \pm 4.6$ & \multirow{2}{*}{$\mathrm{P}=0.003$} \\
\hline & More than 8 hours & $97.3 \pm 3.5$ & \\
\hline
\end{tabular}

\section{Discussion}

Different stressors and job dissatisfaction lead to absenteeism and job abandoning, work-related accidents and lack of productivity. Finally, it should be noted that by identifying the factors and sources of occupational stress, they can be more effectively eliminated. This is important in terms of the socio-economic dimensions of any human system. Because it has been observed that occupational stress has a direct relationship with person's mental, physical and physical health. It has also been observed that its association with cardiovascular diseases also increases the treatment and organization cost. Hence, the general health of the staff in every system will result in increased productivity and reduced costs of the system and even national costs $(18,19)$. Job stress is one of the important factors in the development of physical and psychological complications, as well as job dissatisfaction among health 
care workers and, consequently, lowers the quality of services provided. Physical and mental health of health care workers can directly and indirectly affect the public health level.

Regarding the role of health and medical staff responsible for preventive care in our health care system and improving their job status in improving the quality of services in health systems, this study examines the occupational stress of Kashan University of Medical Sciences staff and its associated factors, which can be implemented to eliminate the stress of the employees of the staff and improve the delivery of services.

In our study, the majority of people had an associate degree. And the diploma degree was second. In the study of Hassanzadeh, which was carried out on employees of the gas company of Kurdestan province, it was observed that $55.4 \%$ had diplomas, $21.9 \%$ of them had an associate degree (20), also in the study of Jamalodini et al. (2016), investigating the sources of job stress and ways to adapt to it in the staff of Qazvin University of Medical Sciences during 2016, it was found that most of the staff $(55 \%)$ had an associate degree (21)

In the carried-out study, occupational stress was studied in 132 female employees of Kashan University of Medical Sciences. At the end of the survey, only two variables of 'working hours' and 'workplace of employees' were significantly correlated with occupational stress (P-value $<0.05$ ), working hours greater than 8 hours were a factor in increasing the worker's stress and balancing the working hours can help reduce the stress of this staffing team. This stress was not different between different levels of education as well as formal or contractual employees, and everyone was at the same level of exposure to job stress. Belkic et al., in Yugoslavia, evaluated various aspects of job stress and concluded that occupational stress factors were 'a low level of income' and 'long and prolonged working hours'. On the other hand, these researchers have expressed that most of these occupational stresses, at their higher levels, can lead to physical and psychological illnesses (3). These results are not consistent with the results of this study.

In a study by Khatuni, which is relatively close to our study, it was observed that work load is the main stress factor among the accountants of Qazvin University of Medical Sciences, and then the organizational environment and responsibility are in the next places (22). In the current study, also, people who earn less than 500,000 tomans have lower job stress scores. Kabirzadeh et al. found that job stress also increased with increasing job responsibilities (23) and his justification for this is that those with a higher income often have more responsibility, which is consistent with the results of our study.

\section{Conclusion}

In the present study regarding the job stress of staff working in Kashan University of Medical Sciences, the stress level was higher in those who work more hours and are employed in university deputies. Given the bad effect that occupational stress can have on employees' physical and mental health, it is important to reduce the hours of work to the standard working hours of other countries, as well as the periodic shift of employees from the deputies to faculties, because this can prevent increasing job stresses more than ever, in which case the efficiency of this important group at the university will boost.

\section{References}

1. Aghilinezhad M, Mohammadi S, Afkari ME, Abbaszadeh D. Surveying the association between occupational stress and mental health, personality and life stressful events in Tehran police officers. Pajouhesh Dar Pezeshki. 2008; 31(4):355-36.

2. Christines DE. Work and organizational Psychology. An Introduction With attitude 2003, P.111-158 Psychology Press, Taylor \& Francis Group, p106-111

3. Belkić K, Nedić O. Occupational medicine--then and now: where we could go from here. Med Pregl. 2014; 67(5-6):139-47.

4. French JRP, Kaplan RD. "Organizational Stress and Individual Strain," in A.J. Marrow, ed., the Failure of Success 4 AMACOM, New York; AMACOM, 1972; 30-66.

5. Sandeep KL. A Study of the occupational stress among teachers. Int J Educ Adm. 2010; 2(2):42132.

6. Seward JP. Occupational stress In: Ladony, editor. Current occupational \& environmental medicine. 3rd Ed. New York: Mc Graw-Hill Company. 2004; 603-18.

7. Azman I. Occupational stress features, emotional intelligence and job satisfaction: an empirical study in private institutions of higher learning. 2010; 16 (5):5-33.

8. Jennifer MC. Stress and job satisfaction among distance educators. Online Journal of Distance Learning Administration. 2006; 9(2):65-90. Available from: www.revistanegotium.org.ve

9. Moorhead G, Griffin R. Organizational Behavior. 7th Ed. New York: Wiley; 2005.

10. Karimzadeh Sh, Razavieh A, Kave MH. The relationship between quality of life (QOL) and selfefficacy (SE) of the teachers from Shahrekord. Shahrekord University of Medical Sciences Journal, 2008; 10(1): 28-35.

11. French JRP, Kaplan RD. Organizational stress and individual strain: The failure of success. New York: Amacom; 1972.

12. Marc Alan Schuckit; "Drug and Alcohol Abuse: A Clinical Guide to Diagnosis and Treatment"; Springer publications; ISBN0387257322; Published 2006.

13. Ras E. Job stress. Khajepoor GR, translator. Tehran: Industrial Management Institute Publication; 1998. \{Persian\}

14. Zare M, Abedi KAD, Halvani GHH, Barkhourdari AAF, Aminpour MR. Prevalence of job stress among staff of the ports and Sailing Corporation of Hormozgan and its relation to nonfatal accidents. J Yazd Univ Med Sci. 2009; 17(3):142-8. (Full text in Persian) 
15. Soori H, Rahimi M, Mohseni H. Association between job stress and work-related injuries: A casecontrol. Iranian Journal of Epidemiology, 2006; 1(2):53-8. (Full text in Persian)

16. Enjezab B, Fernia F. Relationship between jobs stresses and emotional and behavioral responses of midwives employed in public hospitals of Yazd province. J Yazd Univ Med Sci. 2003; 3:32-8.

17. Azad Marzabadi E, Tarkhourani H, Emami Khansari NAS. Job stress in a group of military personnel. Journal of Military Medicine, 2007; 9 (1):15-22. (Full text in Persian)

18. .Chen M, Miller G, Cooper D, Wilson T. Taiwanese junior, college teachers' stress: Counseling implications. Proceedings of the Fifth International Counseling Conference; Hong Kong: International Counseling Association; 1995.

19. Ramezani Nijad R, Hemati Nijad MA, Mohamadi $M$. The study of occupational stressor factors in teachers of physical education and sport. Olympic. 2004;25:27-36. [Persian].
20. Hasanzadeh HA, Shirbeigi N, Olazadeh H. A survey of Job Stress and Productivity among Kurdistan Gas Firm's Staff. Iran Occupational Health Journal. 2012;9(2):1-10.

21. MH Jamalodini, Study the stressors of occupational stress and methods of coping with in Qazvin University of Medical Sciences employers in 2016, Qazvin University of Medical Sciences, 2016, 62P

22. Khatooni M, Mollahasan M, Khoainiha S. Job stress and its related factors in accountant employees of Qazvin University of Medical Sciences. Iran Occupational Health. 2011;8(2):66-76.

23. Kabirzadeh A, Mohsenisaravi B, Asghari Z, Bagherian farabadi E, Bagherzadeh IR. Rate of general health, job stress and factors in medcal records workers. Health Information Manangment. 2007;4(2):215-22. [Persian[

24. Balalian A, Arin, Simonyan, Hambardzum, Hekimian, Kim, Deckelbaum, Richard J., Sargsyan, Aelita. Prevalence and determinants of stunting in a conflict-ridden border region in Armenia - a crosssectional study. BMC Nutrition 3 (1):85. 2017. 10.1186/s40795-017-0204-9. 